\title{
Experience of determining the parameters of the elastoviscoplastic soil model
}

\author{
Armen Ter-Martirosyan, ${ }^{1}$ Artur Manukyan ${ }^{2}$ and Lyubov Ermoshina ${ }^{1 *}$ \\ ${ }^{1}$ Moscow State University of Civil Engineering, Yaroslavskoe shosse, 26, Moscow, 129337, Russia \\ ${ }^{2}$ JSC "Concern MonArch", Moscow, Russian Federation
}

\begin{abstract}
Rheological studies of soils were carried out by S.S. Vyalov, M.N. Gol'dshtejn, N.N. Maslov, G.I. Ter-Stepanyan, S.R. Meschyan, A.L. Gol'din, Z.G. Ter-Martirosyan and many others. On the basis of existing rheological soil models, a new universal rheological equation was proposed in Ter-Martirosyan's dissertation, which allows describing kinematic shear, creep and stress relaxation at the same parameters. Experimental studies of the soil were carried out in a simple shear device in a kinematic loading mode at a shear displacement rate $\dot{u}=0.05 \mathrm{~mm} / \mathrm{min}$ and at two values of compaction loads $\left(\sigma_{1}<\sigma_{2}\right)$. Based on the results of the experimental studies, the parameters of the elastoviscoplastic model were determined and graphs of the dependence of shear stresses on time were plotted, which clearly show the high convergence of the experimental and theoretical curves.
\end{abstract}

\section{Introduction}

Rheology as a science dates back to the 16th century with the derivation of Newton's law of proportionality between the resistance of a fluid to flow and shear rate. The discovery of Poiseuille's law made it possible to establish that the higher the viscosity of a liquid, the lower the volumetric flow rate of this liquid. The derivation of the Nov'e-Stoks equation made it possible to describe the motion of a viscous Newtonian fluid.

A great contribution to the development of soil rheology was made by K. Tercagi, N.P. Puzyrevskij, N.M. Gersevanov, S.S. Vyalov, N.N. Maslov, V.A. Florin, N.A. Cytovich, YU.K. Zareckij, M.N. Gol'dshtejn, A.L. Gol'din, S.R. Meschyan, G.I. Ter-Stepanyan, L. SHukle, A.R. Rzhanicyn, Z.G. Ter-Martirosyan and many others [1-6].

The historical development of soil rheology began with the study of shear creep deformations in soils. S.S. Vyalov in his book [7] mentions that the phenomenon of creep during shear is caused by the processes of hardening (the process of decaying creep) and softening of the soil (the development of the process of continuous creep). M.N. Gol'dshtejn believed that shear disrupts and restores contacts between mineral particles in the skeleton of clay soil [8]. N.N. Maslov proposed to take into account the change in the viscosity of the soil skeleton over time in order to take into account the hardening of clay soil during shear [9]. G.I. Ter-Stepanyan, on the basis of experimental studies of clay for

\footnotetext{
${ }^{*}$ Corresponding author: cool.swimmer2014@yandex.ru
} 
several years in an annular shear device, revealed an abrupt change in shear deformation under a constant load $[10,11]$. To describe the creep of soils, S.R. Meschyan, A.L. Gol'din i Z.G. Ter-Martirosyan applied the Boltzmann-Volterra theory of hereditary creep. This theory in relation to soils was first used by V.A. Florin and later developed by N.N. Maslov and N.H. Arutyunyan to describe the creep process of hardening media, in particular concrete.

K. Bolei and L.A. Strokova [12], on the basis of experimental studies performed, showed that the time of action of the compressive load before carrying out shear tests has a significant effect on the structure and properties of clays, which undoubtedly affects the strength and creep indicators of clay soil.

Merita Tafili and Theodoros Triantafyllidis proposed a simple hypoplastic clayey soil model that includes eight parameters that can be determined and to calibrated from standard laboratory tests [13].

Ren, P., Wang, P., Zhang, H., Tang, Y. conducted experimental studies to study the rheological properties of clay. In this work, a nonlinear creep model was proposed using fractional derivatives and a small number of parameters, capable of describing the entire process of clay creep [14].

In [15], a new model of nonlinear creep is proposed, which makes it possible to describe the creep of frozen sand under various conditions, which was confirmed by experimental studies.

In [16], creep equations were proposed that reflect the nonlinear rheological characteristics of swelling soils. The research results showed that the proposed model describes well the viscoelastoplastic deformation of the creep of the swelling soil, and the results of the analysis of this model are close to the results of the tests carried out.

Haghighat E., Rassouli F.S. and others [17] have developed a viscoplastic model capable of describing the creep characteristics and plastic deformation of the rock during loading-unloading cycles. This model was verified by triaxial testing of soil samples.

In [18], a seven-component rheological model was proposed to describe the behavior of a soft soil under various loading conditions.

\section{Materials and Methods}

To describe the rheological properties of the soil skeleton, the following rheological soil models are currently widely used in engineering practice: Newton's simplest model $-\dot{\gamma}=\frac{\tau}{\eta}$ the Kelvin-Fojgt model $-\dot{\gamma}=\frac{\tau-\gamma \cdot G}{\eta}$, the Maxwell model $-\dot{\gamma}=\frac{\tau}{\eta}-\frac{\dot{\tau}}{G}$, the Shvedov model $-\dot{\gamma}=\frac{\left(\tau-\tau^{*}\right)}{\eta}+\frac{\tau}{G}$, the modified Timoshenko model $-\dot{\gamma}=\frac{\tau}{\eta} \cdot \frac{\tau^{*}}{\tau^{*}-\tau}$. Each model contains a number of parameters that are subject to experimental determination. However, the more complex the model, the more parameters must be determined with sufficient accuracy on the basis of experimental studies, which is not always possible to implement.

In the dissertation of Ter-Martirosyan [19], a new equation for the creep of soils during shear was proposed, which was based on the Bingam-Shvedov-Maslov model:

$$
\dot{\gamma}=\frac{\tau-\tau^{*}(t)}{\eta_{0}} \cdot\left(\frac{e^{-\alpha \gamma}}{a}+\frac{e^{\beta \gamma}}{b}\right)+\frac{\dot{\tau}}{G},
$$

where $\alpha, \beta, a, b$ are the parameters of hardening and softening of clay soil, determined from the results of the experiment. 
This equation is universal and allows one to describe the tests of soil samples, both in the stress relaxation mode and when testing in the kinematic loading mode $(\dot{\gamma}=$ const $)$. Also, this equation allows you to describe the most important rheological property of the soil as creep.

When testing in stress relaxation mode, it is necessary to integrate an equation of the form:

$$
\dot{\tau}+\frac{\tau}{\eta_{0}} \cdot G \cdot\left(\frac{e^{-\alpha \gamma}}{a}+\frac{e^{\beta \gamma}}{b}\right)=\frac{\tau^{*}}{\eta_{0}} \cdot G \cdot\left(\frac{e^{-\alpha \gamma}}{a}+\frac{e^{\beta \gamma}}{b}\right),
$$

When testing soil samples in a kinematic loading mode $(\dot{\gamma}=$ const $)$ and plotting the graphs of the dependence $(\tau-t)$, it is necessary to integrate the following equation:

$$
\dot{\gamma}=\frac{\tau-\tau^{*}}{\eta_{0}} \cdot\left(\frac{e^{-\alpha \gamma}}{a}+\frac{e^{\beta \gamma}}{b}\right)+\frac{\dot{\tau}}{G}
$$

To study the rheological properties of dispersed soils, laboratory tests were carried out on certified equipment manufactured by «NPP Geotek» (on a simple shear device), which includes a shear device for creating a horizontal load, a measuring system and software. The general view of the device on which the twin samples of dispersed soils were tested by the simple shear method is shown in Figure 1.

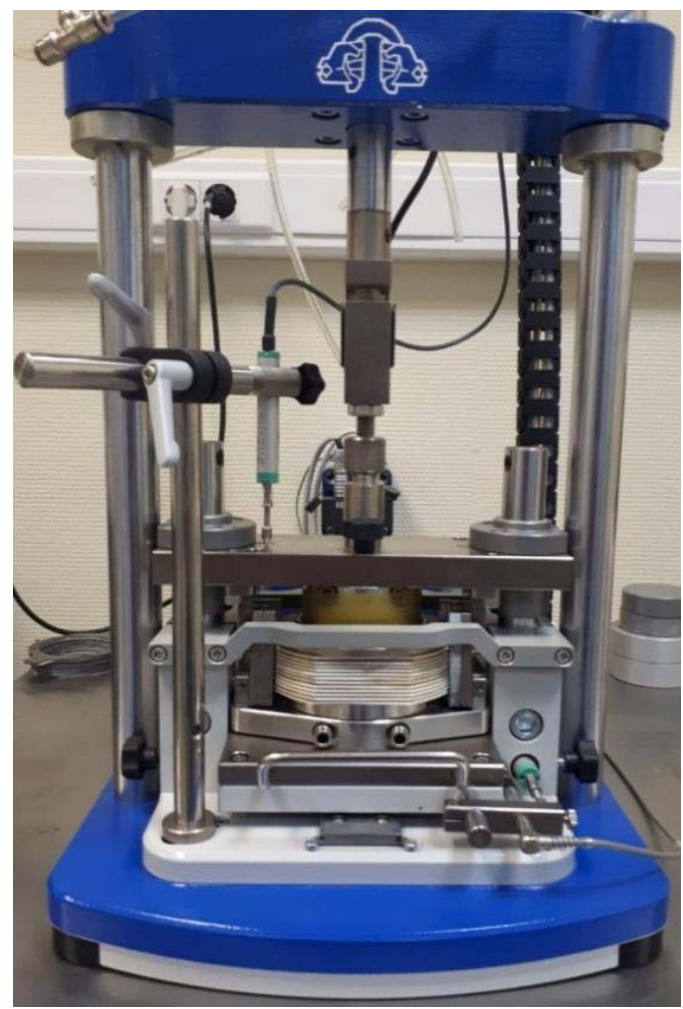

Figure 1. Simple shear device manufactured by «NPP Geotek».

ASTM D6528-2007 "Standard Test Method for Consolidated Undrained Direct Simple Shear Testing of Cohesive Soils" [20] was adopted as the normative document that regulates the performance of tests by the simple shear method. There are currently no Russian normative documents for this type of testing. 
A loam with a plasticity index $I_{p}=10.59$ and a liquidity index $I_{L}=0.797$ (fluid-plastic loam) was taken as a test soil sample. The tests were carried out at soil density $\rho=2.19$ $\mathrm{g} / \mathrm{cm}^{3}$ and moisture $w=0.22$. Dimensions of the tested soil sample: diameter $-71.4 \mathrm{~mm}$, height $-22 \mathrm{~mm}$.

A soil sample was placed in a rubber sheath surrounded by brass and PTFE rings (12 PTFE and 13 brass rings). The rings alternate with each other to reduce friction between them. Porous discs were installed in the upper and lower parts of the sample for drainage during compaction. For tighter adhesion of the soil sample, the porous discs have a ribbed surface.

The tests were carried out in a kinematic loading mode $(\dot{\gamma}=$ const $)$ at a rate shear displacement of $\dot{u}=0.05 \mathrm{~mm} / \mathrm{min}$ and at two values of the compressive loads $\left(\sigma_{1}<\sigma_{2}\right)$. The tests were carried out until the ultimate relative shear strain was reached $\varepsilon=42 \%$ (of the height).

\section{Results}

After replacing $\gamma$ with $\dot{\gamma} t$, we transform equation (3) to the following form:

$$
\frac{\tau}{\eta_{0}} \cdot G \cdot\left(\frac{e^{-\alpha \dot{y} t}}{a}+\frac{e^{\beta \dot{y} t}}{b}\right)+\dot{\tau}=\frac{\tau^{*}}{\eta_{0}} \cdot G \cdot\left(\frac{e^{-\alpha \dot{y} t}}{a}+\frac{e^{\beta \dot{y} t}}{b}\right)+\dot{\gamma} \cdot G
$$

In the MathCad software using the "Odesolve" function, a graph of the dependence of shear stresses on time $(\tau-t)$ was plot, which almost completely coincides with the graph obtained from the results of experimental studies of clay soil in a simple shear device (Figure 2).

To plot the function graph $(\tau-t)$, equation (4) in the MathCad software was written in the following form:

$$
\frac{\tau(t)}{\eta} \cdot G+\tau^{\prime}(t)=\frac{\tau}{\eta} \cdot G+\dot{\gamma} \cdot G
$$

where $\eta=\frac{\eta_{0}}{\left(\frac{e^{-\alpha \dot{y} t}}{a}+\frac{e^{\beta \dot{\gamma} t}}{b}\right)}$.

The initial viscosity $\left(\eta_{0}\right)$, shear modulus $(G)$ and parameters of hardening and softening of clay soil $(\alpha, \beta, a, b)$ were determined directly from the experimental curves in order to obtain the greatest convergence of the experimental and theoretical graphs. 


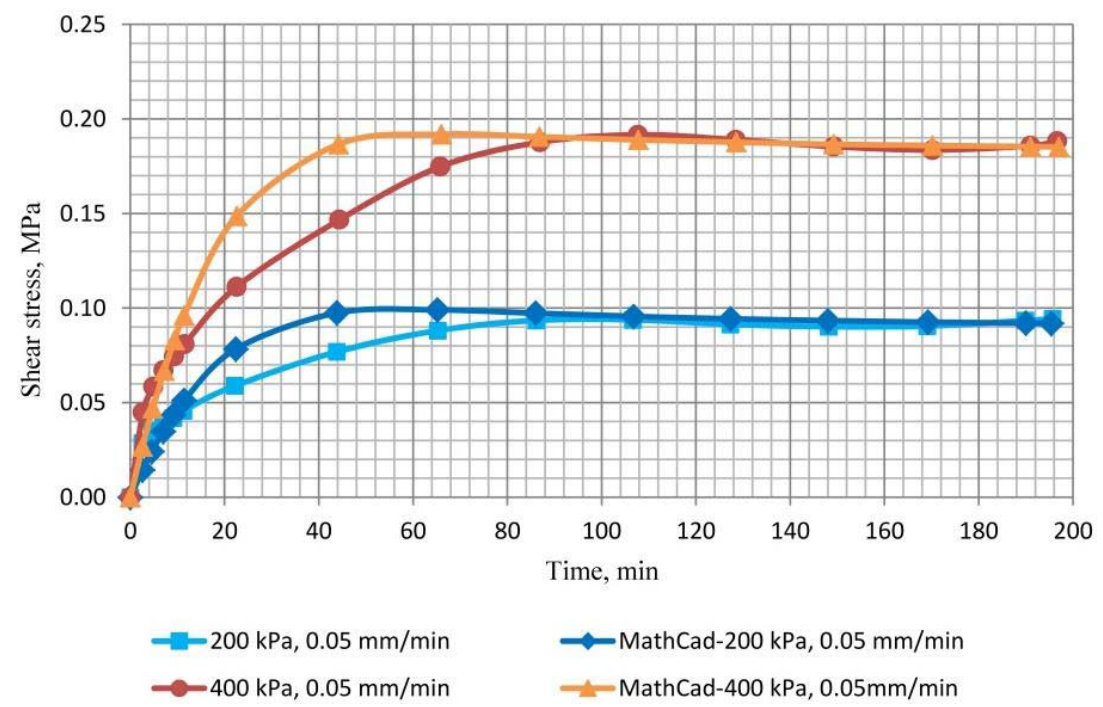

Figure 2. The graph of the dependence of shear stresses on time $(\tau-t)$

Table 1 shows the obtained parameters of the equation.

Table 1. Equation parameters.

\begin{tabular}{|c|c|c|c|c|c|c|c|c|}
\hline $\begin{array}{c}\sigma_{1} \\
\mathrm{kPa}\end{array}$ & $\tau^{*}, \mathrm{kPa}$ & $\dot{\gamma}, 1 / \mathrm{min}$ & $\eta_{0}, \mathrm{kPa} * \mathrm{~min}$ & $G, \mathrm{kPa}$ & $\alpha$ & $\beta$ & $a$ & $b$ \\
\cline { 1 - 6 } 200 & 90.2 & 0.002272727 & 84304 & 412.72 & 7.0 & 5.5 & 0.9 & 0.1 \\
\cline { 1 - 7 } & 183.6 & & & & & \\
\hline
\end{tabular}

\section{Discussion}

Based on the results obtained, the following main conclusions can be drawn:

1. In the course of the study, experimental studies of clay soil were carried out in a simple shear device in a kinematic loading mode $(\dot{\gamma}=$ const $)$ at a rate shear displacement of $\dot{u}=0.05 \mathrm{~mm} / \mathrm{min}$ and at two values of the compressive loads $\left(\sigma_{1}<\sigma_{2}\right)$.

2. The parameters of the elastoplastic soil model were determined on the basis of experimental data, and graphs of the dependence of shear stresses on time $(\tau-t)$ were constructed.

3. A high convergence of the experimental and theoretical curves is shown, which indicates the correctness of the model parameters obtained.

4. In order to more accurately describe the convergence of the graphs, experimental studies should be continued to clarify the methodology for determining the parameters of the elastoplastic soil model.

The reported study was funded by RFBR, project number 20-31-90076.

All tests were carried out using research equipment of The Head Regional Shared Research Facilities of the Moscow State University of Civil Engineering. 


\section{References}

1. Z.G. Ter-Martirosyan. Rheological parameters of soils and calculations of the foundations of structures. M.: Strojizdat. p.200 (1990)

2. T.SH. SHirinkulov, YU.K. Zareckij. Creep and soil consolidation. Tashkent.: Fan. p.392 (1986)

3. YU.K. Zareckij. Viscoplasticity of soils and calculations of structures. M.: Strojizdat. p.352 (1988)

4. S.R. Meschyan. Rheological processes in clayey soils, taking into account special influences. Er.: Ajastan. p.395 (1992)

5. S.R. Meschyan. Experimental rheology of clay soils. Er.: Gitutyun. p.498 (2005)

6. K. Tercagi. Soil mechanics theory. M.: Gosstrojizdat. p.507 (1961)

7. S.S. Vyalov. Rheological foundations of soil mechanics: textbook manual for construction universities. M.: Vysshaya shkola. p.447 (1978)

8. M.N. Goldshtejn. Mechanical properties of soils. M.: Strojizdat. p.256 (1977)

9. N.N. Maslov. Fundamentals of Engineering Geology and Soil Mechanics. M.: Vysshaya shkola. p.511 (1982)

10. G.I. Ter-Stepanyan. The phenomenon of jump-like rearrangement of soil structure during deformation. Engineering Geology 3, 11-26 (1988)

11. G.I. Ter-Stepanyan. Investigation of the creep of clay soils during shear. In the book: Proceedings of the XIII International Conf. on soil mechanics and foundation engineering (1972)

12. K. Bolej, L.A. Strokova. Determination of the creep characteristics of clay soils. Bulletin of the Tomsk Polytechnic University 2, 42-44 (2007)

13. M. Tafili, T.A. Triantafyllidis. simple hypoplastic model with loading surface accounting for viscous and fabric effects of clays. International Journal for Numerical and Analytical Methods in Geomechanics 44(16) 2189-2215 (2020)

14. P. Ren, P. Wang, H. Zhang and Y. Tang. Nonlinear behavior of clay creep and its fractional derivative creep model. Gongcheng Lixue/Engineering Mechanics 37(9) 153160, 207 (2020)

15.Z-Y. Zhu, F. Luo, Y-Z. Zhang, D-J. Zhang and J-L. He. A creep model for frozen sand of Qinghai-Tibet based on Nishihara model. Cold Regions Science and Technology 167(102843) (2019)

16. X. Ning, H. Xiao, C. Zhang, B. He and J. Xie. Study on the nonlinear creep model of expansive soil. Journal of Natural Disasters 26(1) 149-155 (2017)

17. E. Haghighat, FS. Rassouli, M.D. Zoback and R. Juanes. A viscoplastic model of creep in shale Geophysics 85(3) MR155-MR166 (2020)

18. R.G. Gu, Y. Zou, Y.G. Fang and Y.G. Hu. Rheological model of soft soils using nonlinear instantaneous elastic modulus. Yantu Lixue/Rock and Soil Mechanics 39(1) 237-241 (2018)

19. A.Z.Ter-Martirosyan. The interaction of the foundations of buildings and structures with a water-saturated base when taking into account the nonlinear and rheological properties of soils: Dissertation of the doctor of technical sciences: 05.23.02 (Moscow: NRU MGSU) 324 p (2016)

20. ASTM D6528 2007 Standard test method for consolidated undrained direct simple shear testing of cohesive soils (USA: ASTM International). 